\title{
NOVO CÓDIGO FLORESTAL BRASILEIRO E A CONTEXTUALIZAÇÃO DAS MUDANÇAS NAS APPS DE UM RIO URBANO: ESTUDO DO RIO PITIMBU-RN
}

\author{
Helânia Pereira da Silva ${ }^{(a)}$ \\ (a) Programa de Pós em Geografia/Universidade Federal do Ceará- UFC, helaniageo@ hotmail.com
}

\section{EIXO TEMÁTICO: USO E OCUPAÇÃO DAS TERRAS E LEGISLAÇÃO AMBIENTAL}

\begin{abstract}
Resumo
O Novo Código Florestal Brasileiro, Lei no 12.651 de 2012, reafirma as APPs (Áreas de Preservação Permanentes) como áreas frágeis a serem preservadas. Delimitando as faixas protegidas, ressaltando as margens dos rios e toda a sua vegetação. Porém, reformulou-se em conflitos e diante de uma séria dúvida quanto a sua aplicabilidade. Já que existe possibilidade de interpretações errôneas e dificuldade de inseri-lo no planejamento ambiental. Tendo em vista que o uso e ocupação as margens dos rios, as degradam, incluindo ambientes consolidados pelo uso agrícola, industrial e urbano. Assim, este artigo tem por objetivo discutir a importância das APPs do rio Pitimbu - RN, incluindo os principais impactos, e como as mudanças do Novo Código influenciam em sua proteção e, principalmente, mostrar a dificuldade entre o planejamento e a aplicabilidade da lei. Confirmou-se que as APPs do rio Pitimbu sofrem com a degradação ambiental e a falta de políticas públicas efetivas.
\end{abstract}

Palavras- chave: Código Florestal, Áreas de Preservação Permanente, Rio urbano, Rio Pitimbu.

\section{INTRODUÇÃO}

O Novo Código Florestal Brasileiro, a Lei $\mathrm{n}^{\circ} 12.651$ de 2012, reformulou-se em meio a conflitos e interesses antagônicos. Não havendo um vilão definido nessa polêmica trajetória, apenas interesses extremos de setores que lutam e defendem um viés econômico usando espaços naturais já consolidados, longe de uma relação conservadora com ambientes frágeis. Sendo usados por pequenos e grandes agricultores que aproveitam as áreas encharcadas e solos férteis, seguindo um modelo histórico de ocupação do campo brasileiro. Coincidentemente, as margens férteis dos rios. Assim, longe de um ordenamento e de práticas de preservação desses espaços. Relíquias trágicas de um modelo imposto, onde se desmatava primeiro. Visualizava-se a terra exposta, nua e por fim, chegava-se ao financiamento.

Processos que moldaram a relação do homem rural brasileiro em suas formas de cultivar; criar; usar das águas dos rios; dos solos e da flora. Com o Novo Código, a "floresta em pé", adquire valor substancial no momento de financiamentos agrícolas, sendo obrigatória para os produtores, a recuperação de áreas degradadas. O que deverá, teoricamente, impulsionar toda uma cadeia florestal.

Diante das colocações acerca do ordenamento dos espaços naturais, a legislação federal e local estabelece normas e limites, apoiando-se em instrumentos jurídicos como o Novo Código Florestal Brasileiro (Lei no 
12.651 de 2012). Tentando proteger o rio em "sua luta pela sobrevivência", dando-lhe o direito de seguir seu curso, sem impactos negativos pelo homem. Tornando-o uma paisagem significativa e usual para o bem estar da população.

A faixa de terreno que se estende ao longo das margens dos corpos d’água e, no caso específico, do rio Pitimbu no Rio Grande do Norte, tem recebido atenção especial, quanto ao propósito de preservação da quantidade e qualidade de suas águas, bem como do uso de seu solo. A legislação que trata desse espaço é ampla e perpassa os três níveis governamentais. Instrumentos jurídicos que se complementam. Deste modo, a pesquisa tem por objetivo geral discutir as mudanças do Novo Código Florestal Brasileiro (Lei $\mathrm{n}^{\circ}$ 12.651 de 2012), no tocante as APPs (Áreas de Preservação Permanentes) de um rio urbano, relacionandoo as contradições no momento da espacialização dessas faixas, as quais mostram conflitos de uso e ocupação. Tendo como área de estudo as faixas de Proteção Ambiental no rio Pitimbu/RN. Caracterizado por um curso que adentra áreas rurais e urbanas, partindo da nascente até a sua foz.

\section{DISCUSSÃO DAS ÁREAS DE PRESERVAÇÃO PERMANENTE: A APP COMO INSTRUMENTO PARA A PROTEÇÃO AMBIENTA̧L}

As áreas de preservação permanentes foram criadas para evitar a ocupação de áreas naturais de forma irregular e sem o menor critério de uso. Estão inseridas dentro de uma política ambiental de cunho federal, definida pelo Código Florestal brasileiro e demais leis complementares. São localizadas,espacialmente, próximas as margens dos rios, nascentes, topos de morros e montanhas, serras, encostas, nas restingas, nas bordas dos tabuleiros, ou chapadas, e em áreas acima de 1.800 metros. A definição de APP é encontrada no artigo $3^{\circ}$, inciso II, do Novo Códiglo Florestal ( Lei $n^{\circ} 12.651$ de 2012).

Área de Preservação Permanente - APP: área protegida, coberta ou não por vegetação nativa, com a função ambiental de preservar os recursos hídricos, a paisagem, a estabilidade geológica e a biodiversidade, facilitar o fluxo gênico de fauna e flora, proteger o solo e assegurar o bem-estar das populações humanas.

O Novo Código Florestal traz a delimitação das APPs em zonas rurais e urbanas, considerando larguras mínimas entre 30 a 500 metros (variando a largura do rio) para faixas marginais de qualquer rio perene e intermitente, com exceção dos efêmeros, usando o critério da borda da calha do leito regular artigo $3^{\circ}$, "XIX - a calha por onde correm regularmente as águas do curso d'água durante o ano". Assim, a lei estabelece normas gerais para proteção da vegetação; áreas de Preservação Permanentes; as áreas de Reserva Legal; a exploração florestal; o suprimento de matéria-prima florestal; o controle da origem dos produtos florestais; o controle e prevenção dos incêndios florestais, e prevê instrumentos econômicos e financeiros para o alcance de seus objetivos, como o pagamento por serviços ambientais. Conforme artigo 
41, inciso I: "É o Poder Executivo federal autorizado programa de apoio e incentivo à conservação do meio ambiente. I - pagamento ou incentivo a serviços ambientais como retribuição monetária ou não, às atividades de conservação e melhoria dos ecossistemas e que gerem serviços ambientais".

Mostrando no parágrafo $1^{\circ}$, inciso I "afirmação do compromisso soberano do Brasil com a preservação das suas florestas e demais formas de vegetação nativa, bem como da biodiversidade, do solo, dos recursos hídricos e da integridade do sistema climático, para o bem estar das gerações presentes e futuras."Compromisso contraditório com a real aplicabilidade da lei, ao reduzir, ainda mais, o limite de proteção em áreas naturais já difíceis de serem protegidas, como as margens de rios, pois antes, usava-se o critério da calha do leito maior sazonal (os limites das cheias anuais), seguindo uma espacialização prédefinida. Critério alterado para a borda da calha do leito regular. Contribuindo assim, para que atividades agrícolas ou equipamentos urbanos de impacto permaneçam instalados,praticamente, dentro das planíceis de inundação dos rios. Consolidando, não a preservação, e sim, impactos à qualidade das águas, e dos recursos naturais essenciais para diferentes gerações. Conforme o artigo $3^{\circ}$, inciso IV - "área rural consolidada: área de imóvel rural com ocupação antrópica preexistente a 22 de julho de 2008, com edificações, benfeitorias ou atividades agrossilvipastoris, admitida, neste último caso, a adoção do regime de pousio".

Metzger (2010) discute sobre as dúvidas em relação ao embsamento científico que permitiu os parâmetros e os critérios do Código Florestal Brasileiro. O código estipula uma série de larguras mínimas e áreas de proteção ao longo de cursos d’ água, reservatórios,e nascentes. O autor questiona então, qual a base científica usada para definir quais corredores ripários deveriam ter no mínimo 30 metros de proteção ao longo de cada margem do rio. Outra dúvida é se essa largura não deveria variar com a topografia da margem, com o tipo de vegetação, ou o clima em particular com a pluviosidade local.

Outro ponto contraditório no Código Florestal é o uso da unidade territorial do módulo fiscal para delimitar a faixa de preservação dos corpos d` àgua em espaços rurais consolidados, em propriedades de 1 a 4 módulos fiscais. Colocando não mais a largura do rio como critério, mas sim, o tamanho da propriedade. Usando um mínimo de 5 a 15 metros para faixas marginais de proteção. Estabelecido pelo artigo 61-A. Colocando ainda em seu parágrafo § 50 "Nos casos de áreas rurais consolidadas em Áreas de Preservação Permanente no entorno de nascentes e olhos d'água perenes, será admitida a manutenção de atividades agrossilvipastoris, de ecoturismo ou de turismo rural, sendo obrigatória a recomposição do raio mínimo de 15 (quinze) metros".

Assim, revela a subjetividade e a falta de um estudo científico na delimitação das APPs, quando diferencia as faixas pelo uso e ocupação, reduzindo ainda mais a proteção, principalmente em nascentes e olhos d’água, espaços naturais frágeis e citados, pela própria lei (Conforme artigo 41, inciso I), como 
objeto de conservação e proteção, para assegurar os seus serviços ambientais. Para Whately e Hercowitz (2008) "o termo serviços ambientais é definido de diversas formas na literatura especializada, podendo também ser identificado como serviços ecossistêmicos ou serviços ecológicos".

Para Millennium Ecosystem Assessment (2003) os serviços dos ecossistemas são os benefícios que as pessoas recebem dos ecossistemas. Estes incluem serviços de produção como alimento e água; serviços de regulação de enchentes, de secas, da degradação dos solos, e de doenças; serviços de suporte como a formação dos solos e os ciclos de nutrientes, e serviços culturais como o recreio, valor espiritual, valor religioso e outros benefícios não-materiais

Para Metzer (2010), é importante pensar nas larguras das faixas de proteção com critérios que envolvam as suas múltiplas funções, desde a fixação do solo, proteção dos recursos hídricos, conservação da fauna e flora, ou seja estabelecer larguras mínimas adequadas e suficientes. Pois, estas afetam a qualidade do habitat, regulando as áreas impactadas pelos efeitos de borda. Os efeitos de borda que são aqueles causados pela variação de processos naturais e antrópicos como: aumento ou diminuição da luminosidade, queimadas, ressecamento do ar, do solo, entrada de espécies invasoras.

Assim, os efeitos mais intensos ocorrem nos 100 primeiros metros, daí corredores com menos de 200 metros são formados essencialmente por ambientes de borda altamente perturbados. Neste sentido espécies mais florestais,ou seja, espécies menos generealistas, necessitam de áreas naturais com pelo menos 200 metros de largura. A relação com a vegetação está atrelada, principalmente, a proteção dos recursos hídricos que vêm em primeira instância. A supressão de uma APP deve ser verdadeiramente uma exceção. Não poder ser facilitada, pois é essencial para a vida. (MACHADO, 2007, p. 740). Conforme o artigo $7^{\circ}$ do Código Florestal:

A vegetação situada em Área de Preservação Permanente deverá ser mantida pelo proprietário da área, possuidor ou ocupante a qualquer título, pessoa física ou jurídica, de direito público ou privado.§ $1^{\circ}$ Tendo ocorrido supressão de vegetação situada em Área de Preservação Permanente, o proprietário da área, possuidor ou ocupante a qualquer título é obrigado a promover a recomposição da vegetação.

É nesse sentido que a própria legislação, muitas vezes, é contraditória e difícil de ser entendida, indicando uma gestão ambiental barrada pelos entraves judiciais. E ainda dificultando o ordenamento do território, pois ao longo de um mesmo rio, teríamos faixas diferentes relacionadas a existência, ou não, de cobertura vegetal, formando um mosaico de faixas consideradas no conceito de proteção, e outras não.Na carta européia do ordenamento do território (DGOT, 1988, p. 9 e 10) o ordenamento é a tradução espacial da política econômica, social, cultural e ecológica da sociedade. É, simultaneamente, uma disciplina 


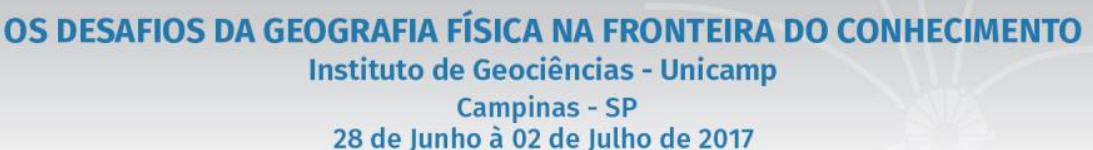

científica, uma técnica administrativa e uma política que se desenvolve numa perspectiva interdisciplinar e integrada.

Assim, torna-se difícil ordenar áreas frágeis, como margens de rios, quando estas são sufocadas pelas edificações e por inúmeras obras, muitas vezes consideradas de interesse público ou de baixo impacto ambiental, confrontando-se com a restrição da própria lei. Exemplificando o artigo $3^{\circ}$, inciso IX e X do Código Florestal, ao colocar uma série de atividades como eventuais ou de baixo impacto, ou ainda liberar essa definição em ato do Conselho Nacional do Meio Ambiente - CONAMA ou dos Conselhos Estaduais de Meio Ambiente. Fortalecendo-se também pelo artigo $3^{\circ}$, inciso VI - "uso alternativo do solo: substituição de vegetação nativa e formações sucessoras por outras coberturas do solo, como atividades agropecuárias, industriais, de geração e transmissão de energia, de mineração e de transporte, assentamentos urbanos ou outras formas de ocupação humana"

Assim, o artigo $8^{\circ}$ traz que "a intervenção ou a supressão de vegetação nativa em Área de Preservação Permanente somente ocorrerá nas hipóteses de utilidade pública, de interesse social ou de baixo impacto ambiental, previstas na lei". Ou ainda, conforme o artigo 26 "A supressão de vegetação nativa para uso alternativo do solo, tanto de domínio público como de domínio privado, dependerá do cadastramento do imóvel no CAR, e de prévia autorização do órgão estadual competente do Sisnama".

Mas, quem garante que os atores sociais do espaço em questão ponderam os impactos ao construírem, ou modificarem tais áreas para eventuais interesses de crescimento urbano e econômico? Ou que os mesmos farão um uso alternativo do solo dentro de padrões ambientais? É questionável a flexibilidade do uso alternativo do solo, liberando-o apenas pelo CAR (cadastro ambiental rural). Documento que não supri por completo, as informações de fragilidade das propriedades rurais. Algo quantitativo, e não qualitativo. E ainda, sem relacionar o tipo de atividade com o bioma explorado, pois há adaptações diferentes para cada região do país. E existirá realmente, fiscalização quanto a adoção de medidas compensatórias e mitigadoras que assegurem a conservação dessas áreas?

Deste modo, podem justificar seus licenciamentos voltados a um "interesse comum", quando essas "benfeitorias", nem ao menos atingem classes de baixa renda, instaladas em áreas urbanas precárias e periféricas. Espaços, historicamente, conflituosos quanto a sua fragilidade urbana e ambiental. E não há, ainda, garantia de que atividades liberadas e colocadas como sustentáveis, adotem de fato, tais regulamentações. Pois, um processo considerado de baixo impacto para um ambiente natural, pode não ser considerado em outro. Guerra e Cunha (2010, p. 27) denotam que os problemas ambientais, ecológicos e sociais não atingem igualmente todo o espaço urbano. Atingem muito mais os espaços físicos de ocupação das classes sociais menos favorecidas do que os das classes mais elevadas. 


\section{OS DESAFIOS DA GEOGRAFIA FÍSICA NA FRONTEIRA DO CONHECIMENTO \\ Instituto de Geociências - Unicamp \\ Campinas - SP \\ 28 de Junho à 02 de Julho de 2017}

Para Metzer (2010) não se pode, porém, dizer que haja estudos técnicos e científicos que sustentem os critérios definidos para mensurar tais faixas ambientais, pois essas áreas naturais possuem características pedológicas, geomorfológicas e hidrológicas distintas. A legislação ambiental brasileira, contudo, traz sérios principios de proteção as APPs, mas na prática é esquecida quando confrontada com os interesses particualares de atores que reordenam os espaços naturais, utilizando-os de acordo com a demana econômica, poluindo as fontes limpas, degradando os solos, fauna e flora locais.

\section{MATERIAL E MÉTODOS}

\section{ÁREA DE ESTUDO}

O rio Pitimbu localiza-se na região litoral oriental do Estado do Rio Grande do Norte, fazendo parte da bacia do Pirangi, com uma área de $460 \mathrm{Km}^{2}$, composta pelos rios Pium e rio Pitimbu (Figura 1). Em seu curso percorre os municípios de Macaíba, Parnamirim, e Natal. Integrantes da região metropolitana do Natal. O rio nasce na comunidade de lagoa seca, área rural do município de Macaíba.

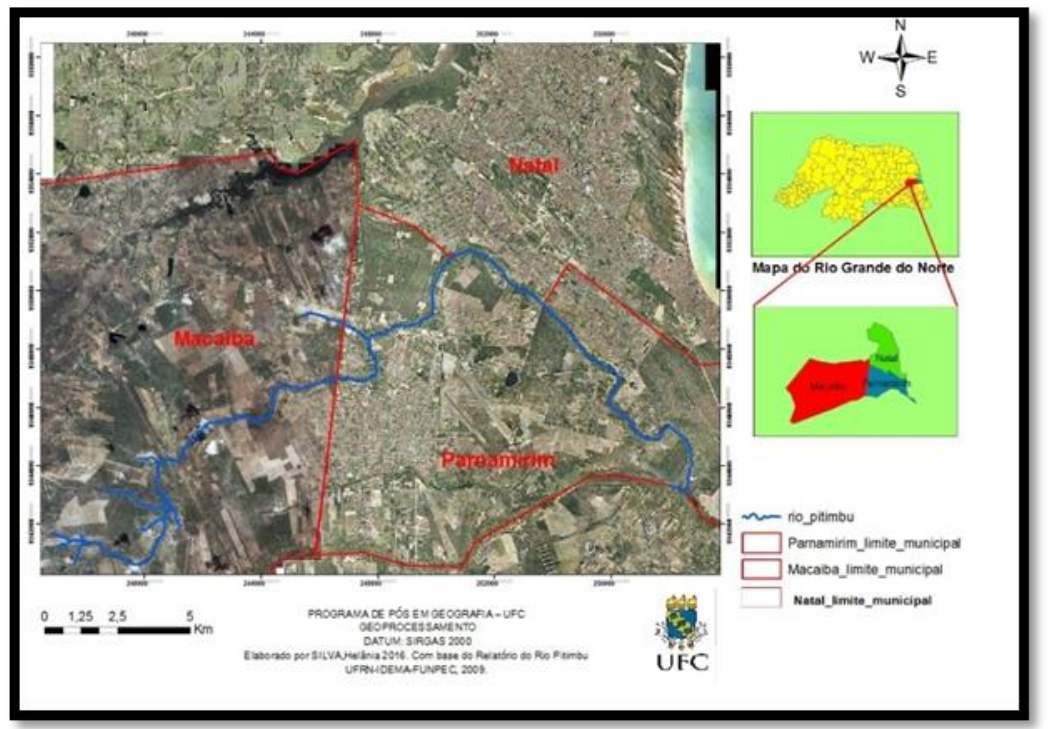

Figura 1- Mapa do rio Pitimbu

Fonte: Silva, Helânia 2016. Relatório do rio Pitimbu-UFRN-IDEMA-FUNPEC, 2009.

O rio Pitimbu possui sua origem relacionada aos processos tectônicos, apresentando um traçado morfológico de vale estrutural, onde ocorre o "Graben Parnamirim". Caracteriza-se como um terraço fluvial entalhado por sedimentos oriundos dos processos de acumulação fluvial. (SANTOS, 1999, apud BORGES ET AL., 1999, p.5).

O embasamento litólico da área compreende três formações: Formação barreiras, Depósitos Eólicos e Aluviões, apresentando uma estratigrafia constituída por rochas pré-cambrianas do embasamento 
cristalino, sobrepostos por sedimentos areníticos e calcários com idade geológica Mesozóica e período Cretáceo. As Unidades geológicas componentes da bacia do rio Pitimbu são: Grupo Barreiras, Lagoas, paleocascalheiras, paleodunas. (RELATORIO VBA, 2005). O tipo de clima da área é classificado como As' (tropical chuvoso). Com temperaturas elevadas ao longo de todo o ano. Destacam-se os valores de pluviosidade de $1.380 \mathrm{~mm}$.

Os solos de maior expressão na área da Bacia do Pitimbu são os Latossolos, os quais ocorrem associados aos tabuleiros do grupo Barreiras nas regiões de alto e médio curso da bacia. Na região de baixo curso, já próximo ao litoral observa-se o predomínio das Areias Quartzosas Distróficas. A vegetação natural ocorrente na bacia é a Savana Florestada e como Formações Pioneiras.

\section{PROCEDIMENTOS METODOLÓGICOS}

A pesquisa identificou diferentes classes de uso e cobertura do solo nas faixas de proteção ambiental do rio Pitumbu. Revelando uma série de conflitos quanto ao uso desse solo. Os mapas foram confeccionados com base no Manual técnico de uso da terra (IBGE, 2006), bem como materiais sobre ordenamento territorial; legislação ambiental específica; segurança hídrica e gestão de áreas frágeis. Com etapas referentes a base cartográfica, coleta de dados em campo. E confecção de mapas temáticos (Figura 2).

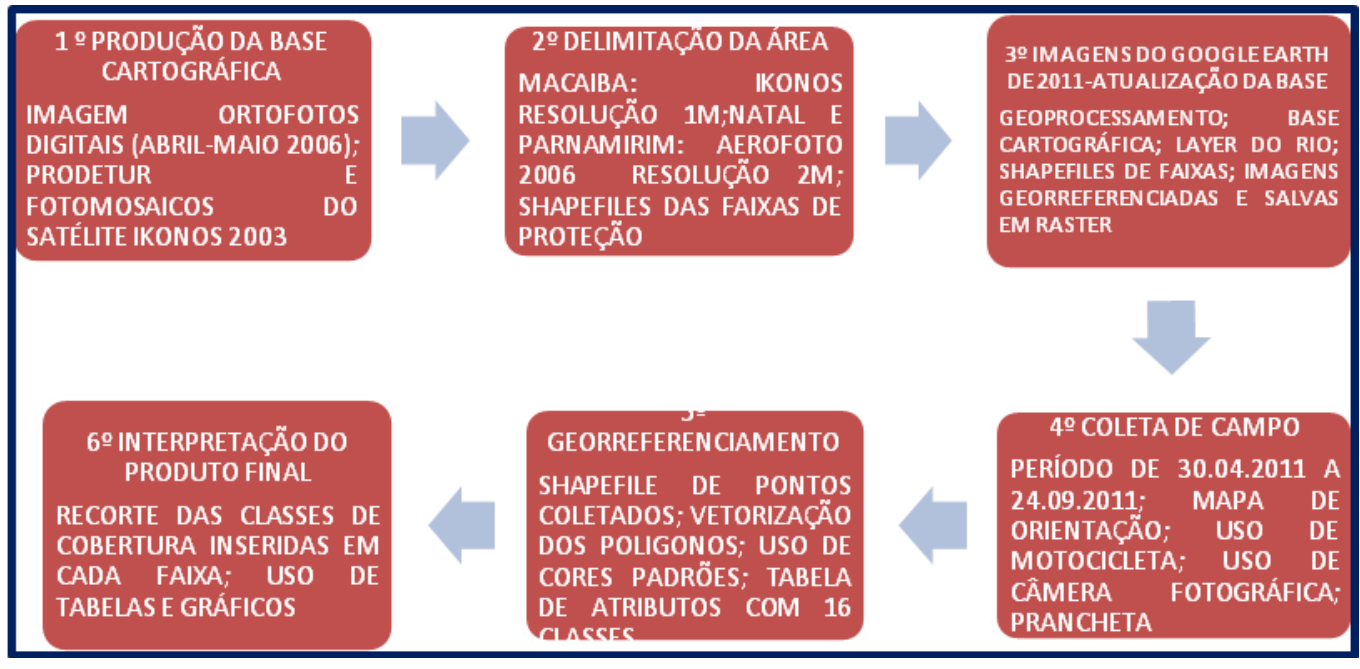

Figura 2- Fluxograma de Etapas da pesquisa. Fonte: SILVA, Helânia, 2016.

\section{RESULTADOS E DISCUSSÃO}

O produto final foi um mapa de cobertura com 16 classes divididas nas categorias: antrópicas, agrícolas, e naturais. Geralmente as atividades humanas estão diretamente relacionadas com o tipo de revestimento do solo, seja ele florestal, agrícola, residencial, ou industrial. A interpretação dos dados de campo apoiou-se 


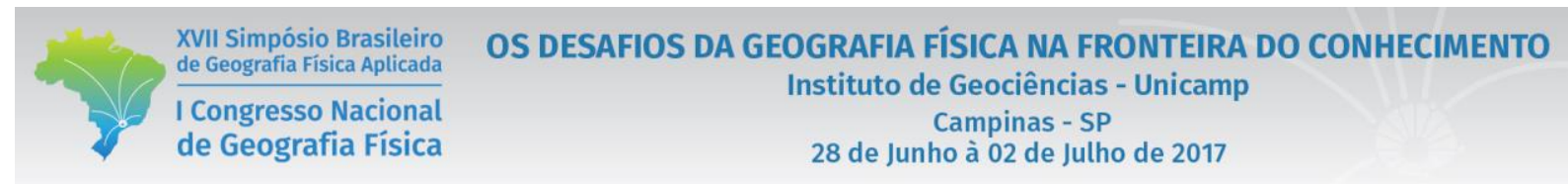

na legislação do Novo Código Florestal, sendo interpretadas classes de uso e cobertura numa faixa de 100 metros.

\section{Cobertura do Solo na APP (Área de preservação Permanente) do rio Pitimbu- RN}

O Mapa abaixo mostra as 16 classes de cobertura do solo encontradas ao longo do rio. Essas correspondem a faixa de 100 metros (Figura 3), conforme o Código Florestal Brasileiro, a Lei no 12.651 de 2012. A cobertura do solo na APP dos três municípios apresenta 16 classes ao todo, de uma área de 943,35 hectares. São 9 antropizadas e 7 naturais. Conforme Tabela abaixo.

Tabela 1 - Área das classes de cobertura do solo na faixa de 100 metros, APP do rio, nos municípios de Macaíba, Parnamirim e Natal, 2011.

\begin{tabular}{|c|c|c|c|c|c|c|c|c|}
\hline \multicolumn{9}{|c|}{ CI.ASSES DE COBERTURA DO SOLO NA APP DO RIO } \\
\hline \multirow[t]{2}{*}{ Classes de cobertura } & \multicolumn{2}{|c|}{ Macaiba } & \multicolumn{2}{|c|}{ Parnamirim } & \multicolumn{2}{|c|}{ Natal } & \multicolumn{2}{|c|}{$\begin{array}{l}\text { Total nos } 3 \\
\text { municípios }\end{array}$} \\
\hline & ha & $\%$ & ha & $\%$ & ha & $\%$ & ha & $\%$ \\
\hline \multirow{2}{*}{$\begin{array}{l}\text { Vegetaçăo herbácea } \\
\text { secundária } \\
\text { Agricultura } \\
\text { permanente }\end{array}$} & 97,82 & 1,46 & 92,14 & 23,09 & 3,99 & 9,55 & 193,95 & 20,56 \\
\hline & 113,15 & 1.64 & 63,77 & 15,98 & 8,28 & 19,79 & 185,20 & 19,64 \\
\hline \multirow{3}{*}{$\begin{array}{l}\text { Savana arborizada } \\
\text { Área construida } \\
\text { Floesta estacional } \\
\text { aluvial }\end{array}$} & 125,23 & 8,07 & 40,20 & 10,07 & - & - & 165,43 & 17,54 \\
\hline & 40,54 & 2,50 & 62,13 & 15,57 & 4,70 & 11,25 & 107,37 & 11,38 \\
\hline & 12,63 & 9.73 & 50,20 & 12,58 & 1,36 & 3,24 & 64,19 & 6,81 \\
\hline \multirow{3}{*}{$\begin{array}{l}\text { A gricultura temporá } \\
\text { Vegetaçào arbórea } \\
\text { secundíria } \\
\text { Savana arborizada } \\
\text { secundária }\end{array}$} & 48,84 & 5.18 & 0.52 & 0,13 & 0.98 & 2,34 & 50,34 & 5,34 \\
\hline & 12,56 & 0,43 & 31,92 & 8,00 & 2,51 & 6,01 & 47,10 & 4,99 \\
\hline & 26,02 & 2.51 & 16,37 & 4,10 & - & - & 42,39 & 4,49 \\
\hline \multirow{4}{*}{$\begin{array}{l}\text { Restinga arbustiva } \\
\text { Floresta estacional de } \\
\text { terras baixas } \\
\text { Pioncira herbioca } \\
\text { influência fluvial } \\
\text { Pioncira arbustiva } \\
\text { influencia fluvial }\end{array}$} & - & - & 12,13 & 3,04 & 19.66 & 47,01 & 31,79 & 3,37 \\
\hline & - & - & 16,87 & 4,23 & - & - & 16,87 & 1,79 \\
\hline & 5,93 & 22,53 & 4,69 & 1,17 & - & - & 10,62 & 1,13 \\
\hline & 8,23 & 1,18 & 1,24 & 0,31 & 0,12 & 0,29 & 9,59 & 1,02 \\
\hline Vegetaçăo ruderal & 2,17 & 0,35 & 5,18 & 1,30 & - & - & 7,35 & 0,78 \\
\hline \multirow{4}{*}{$\begin{array}{l}\text { Pastagem plantada } \\
\text { Rodovia federal } \\
\text { Làmina đágua } \\
\text { TOTAL. }\end{array}$} & 7,31 & 24,94 & - & - & - & - & 7,31 & 0,78 \\
\hline & & & 1,62 & 0,41 & 0,22 & 0,52 & 1,84 & 0,20 \\
\hline & 1,75 & $\overline{19}, 48$ & 0,11 & 0,03 & 0,00 & 0,01 & 1,86 & 0,20 \\
\hline & 502,18 & 100 & 399,09 & 100 & 41,83 & 100 & 943,12 & 100 \\
\hline
\end{tabular}

Fonte: SILVA, Helânia 2011. 
28 de Junho à 02 de Julho de 2017

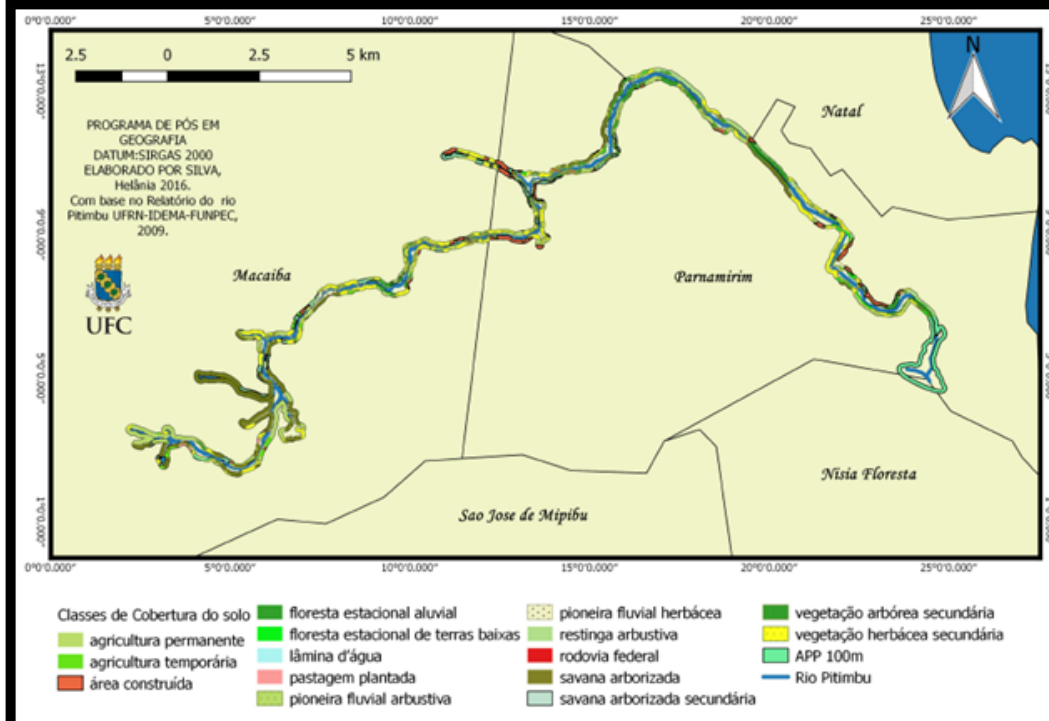

Figura 3- Recorte- Cobertura do solo na APP de 100 metros do rio Pitimbu-RN.

Fonte: SILVA, Helânia 2016. Relatório do rio Pitimbu UFRN-IDEMA-FUNPEC, 2009.

\section{Percentagem e comparativo de classes por município}

Verificou-se que na APP a cobertura antropizada já representa 51,58\% da área. Distribuídas nas seguintes classes: vegetação herbácea secundária (20,56\%); agricultura permanente (19,64\%); área construída $(11,38 \%)$. A cobertura natural é de savana arborizada (17,54\%) e a floresta estacional aluvial $(6,81 \%)$. As demais classes, na categoria outros, são 24,09\% de cobertura (Figura 4).

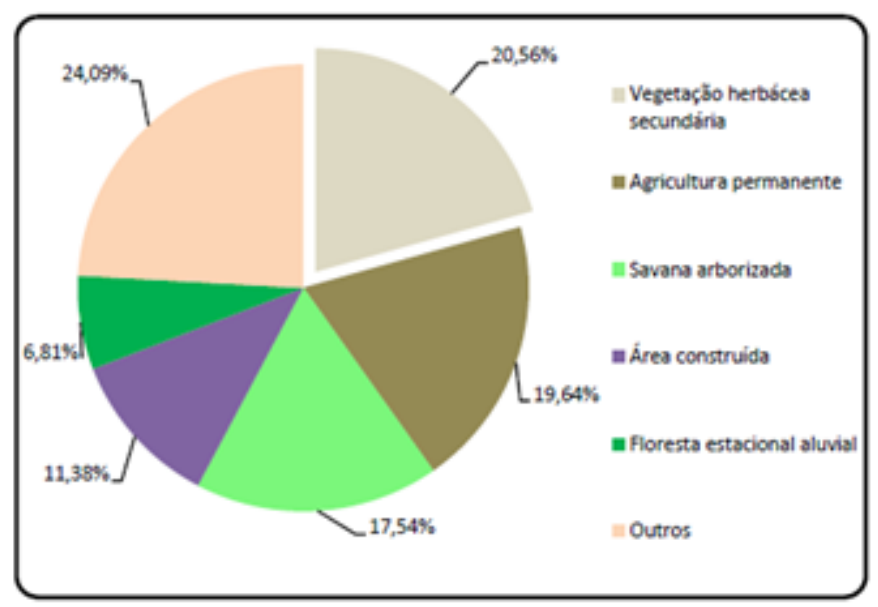

Figura 4- Percentagem das classes de cobertura na APP - 100 metros do rio Pitimbu, nos municípios de Macaíba, Parnamirim e Natal, 2011. Fonte: Silva, Helânia. Nov-2011.

$\mathrm{Na}$ análise das classes por municípios (Figura 5, abaixo) verificou-se que das 5 classes discutidas, o maior percentual de floresta estacional aluvial está em Parnamirim (78,20\%). Cabe lembrar que esta é quase 
inexistente em Natal (2,11\%). Dos três municípios, Macaíba e Parnamirim concentram todas as classes em maiores percentagens. Das classes antropizadas a agricultura permanente $(61,09 \%)$ e a vegetação herbácea secundária (50,43\%) são maiores em Macaíba (Figura 6).

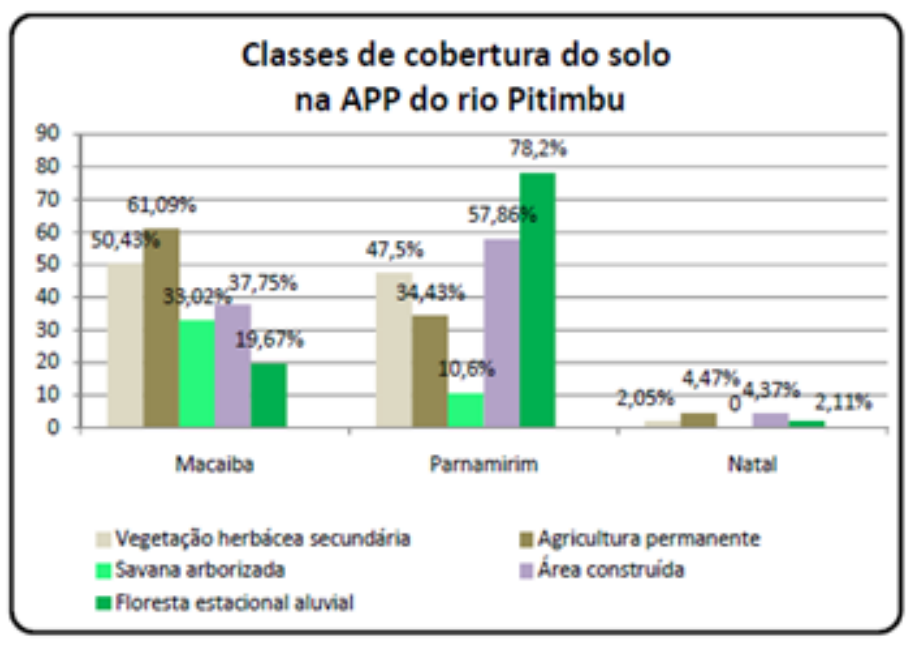

Figura 5- Classes de cobertura do solo, na APP - 100 metros do rio Pitimbu, percentagem por município, 2011. Fonte: Silva, Helânia.Nov-2011.
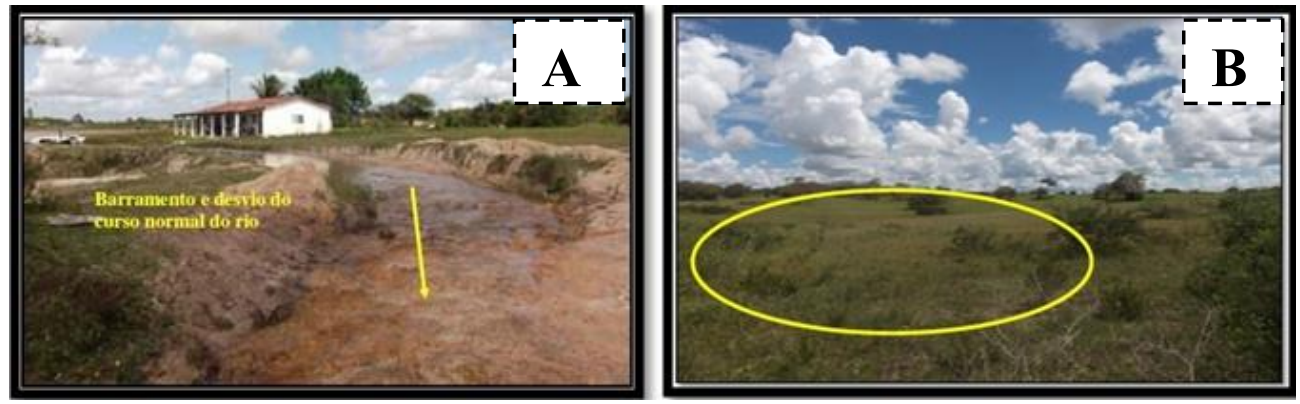

Figura 6 - Fazenda localizada na APP do rio

desvio do curso normal (A), Vegetação herbácea secundária na nascente do rio ( B) Fonte: autora, jul. 2011.

Já Parnamirim concentra o maior percentual de área construída (57,86\%). Quanto às classes naturais a savana arborizada (vegetação de porte baixo) é caracterizada nesse ambiente de tabuleiros, sendo maior em Macaíba.

Em Natal a maior expressão é de agricultura permanente, marcada pelos coqueiros ao longo do rio. Em seguida é o percentual de área construída (4,37\%). Já que se encontram nas APPs alguns condomínios irregulares, degradando a qualidade da água, ao lançar seus efluentes no rio. Isso indica que aos poucos as áreas de grande importância para proteção da qualidade e quantidade da água são substituídas por plantações de mandioca, bananeiras, coqueiros, capim para o gado, construções irregulares. E outras áreas são desmatadas, ficando a espera de algum tipo de cultivo, áreas de pousio. Conforme artigo $3^{\circ}$, inciso 
XXIV. Verificou-e que mais da metade $(51,58 \%)$ da área de Preservação Permanente ao longo dos municípios sofrem impactos pelas atividades do homem e não há restrições por parte dos órgãos fiscalizadores, no sentido de coibir a ocupação. Muito menos projetos de recuperação em todo o seu curso. Considerou-se que nesta faixa não há proteção conforme a legislação vigente, e que aos poucos a vegetação nativa é substituída, ou suprimida, pela agricultura permanente e por vegetação herbácea secundária. Esta faixa está em desconformidade com o artigo $2^{\circ}$ do Código Florestal que traz a proteção as florestas e demais vegetações naturais ao longo dos rios.

A largura delimitada mostrou-se ineficaz para a proteção das APPs e da qualidade das águas do rio, colocando em alerta a segurança hídrica, principalmente, de bairros do município de Natal. Revelando a necessidade de faixas bem maiores para assegurar a proteção da mata ciliar, e do equilíbrio do ecossistema, bem como evitar a sua degradação pelo homem. Porém, lembrando que a urgência não é aumentar as faixas de proteção, mas, fiscalizar as que já estão delimitadas.

Constatou-se que os instrumentos do planejamento ambiental são muitos, mas o gerenciamento dos recursos hídricos, através de práticas de fiscalização e de uma política de educação ambiental séria, deixa a desejar quanto a eficiência da gestão. Não existem projetos para reordenar o uso do espaço urbano evitando que os agentes imobiliários construam seus grandes empreendimentos nessas faixas, descaracterizando essas paisagens naturais, "redutos no meio urbano". Negando diretamente o que traz o artigo 61-A, § 14 do novo Código Florestal: "verificada a existência de risco de agravamento de processos erosivos ou de inundações, determinará a adoção de medidas mitigadoras que garantam a estabilidade das margens e a qualidade da água".

\section{CONSIDERAÇÕES}

Portanto, o novo Código Florestal Brasileiro reformulou-se num cenário tumultuado quanto ao uso das APPs, em específico nos rios. Pois, são espaços de intenso uso, e que diante de uma revisão da lei, perdeu ainda mais seu caráter protetor, no momento da redução das faixas, partindo do leito regular dos rios, e não mais, do leito maior sazonal. Liberando, assim o uso e ocupação de uma faixa ambiental de extrema fragilidade, áreas encharcadas e importantes para assegurar a biodiversidade; a conservação dos solos úmidos; a vegetação ciliar e demais florestas e a disponibilidade dos recursos hídricos para as gerações. Reduzindo, por conseqüência a largura natural dos rios, puramente por interesses econômicos e não conservacionistas.

Assim, não há como assegurar a produção agrícola, a proteção as nascentes e olhos d’água, a mata ciliar e a floresta, se não há proteção de elementos essenciais ao meio. Pois toda atividade econômica necessita dos recursos naturais em bom estado de conservação. E a qualidade de vida da população depende 
diretamente do consumo de água limpa, solos e vegetação menos impactados. O rio Pitimbu é, portanto, foco da legislação federal, mas de poucas concretizações da mesma. Não há em sua extensão, intervenções para recuperação de áreas em processo de degradação, que possam manter a mata ciliar e o estado de conservação do solo.

Deste modo, mesmo, o rio sendo uma representação histórica no processo de criação das cidades, no momento da estruturação da malha urbana, esse é o primeiro a ser esquecido em sua essência de paisagem natural. Tornando-se depósitos de esgotos, e resíduos, sendo soterrados, edificados ou renegados a simples cursos d’água que cortam áreas da cidade, na maioria localizadas nas periferias. Observa-se que os rios sobrevivem como um desenho de uma sociedade de classes, onde os que detêm o poder aquisitivo ocupam, rapidamente, as áreas nobres, altas da cidade. E os mais pobres são sujeitos a se instalarem nessas áreas frágeis rebaixadas.

Nesse sentido, ocorre uma inversão de valores, onde o processo de crescimento urbano desvaloriza as margens dos rios, negando sua paisagem, quando o correto seria a valorização e revitalização dessas margens, preservando a suas funções ecológicas. E resgatando um estilo de vida mais saudável, relacionado a um meio ambiente preservado.

\section{REFERÊNCIA BIBLIOGRÁFICA}

BORGES, A. N. Estudos de impacto ambiental do centro industrial avançado -CIA-RN. (Dissertação de mestrado). Programa de Pós Graduação em Recursos hídricos e Engenharia Sanitária: UFRN, 1999.

BORGES, A. N. Implicações ambientais na bacia hidrográfica do rio Pitumbu (RN) decorrentes das diversas formas de uso e ocupação do solo. (Dissertação de mestrado). Programa da Pós em Engenharia Sanitária, Natal: UFRN, 2002.

CONSELHO NACIONAL DE MEIO AMBIENTE. Resolução CONAMA n 369 de 20 de março de 2006.

DIREÇÃO GERAL DO ORDENAMENTO DO TERRITÓRIO. Carta européia do ordenamento do território. Lisboa: SEALOT-MPAT, 1998.

GUERRA, A. J. T.; CUNHA, S. B. da. Impactos urbanos no Brasil. 6a Ed. Rio de Janeiro: Bertrand Brasil, 2010. . INSTITUTO BRASILEIRO DE GEOGRAFIA E ESTATÍSTICA. Manual técnico de uso da terra. $2^{\mathrm{a}}$ ed. Rio de Janeiro: IBGE, 2006.

METZGER, J.P.O Código Florestal tem base científica?Conservação e Natureza. . São Paulo: USP, 2010.

MILLENNIUM ECOSYSTEM ASSESSMENT. EcosystemsandHumanWel-being: a framework for assessment. Disponível em: http: www.millenniummassessment.org.

MACHADO, P. A. L. Direito ambiental brasileiro. 15 ed. São Paulo: Malheiros, 2007.

MAY, P. H. Economia do meio Ambiente: teoria e prática. Rio de Janeiro: Elsevier, 2010. $2^{\mathrm{a}}$ Ed.

PRESIDENCIA DA REPÚBLICA. Dispoe sobre a proteção da vegetação nativa; altera as leis no 6.938 de 31 de gosto de 1981. Lei no 12.651 de Maio de 2012. 


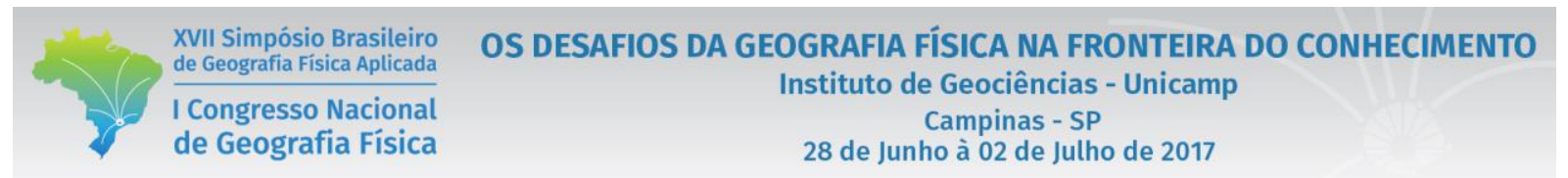

SILVA, H.P. da. Faixas de Proteção Ambiental do rio Pitimbu-RN: uma análise como subsídio ao planejamento e ordenamento do território. (Dissertação de Mestrado). Programa de Pós - Graduação e Pesquisa em Geografia. Natal: UFRN, 2012.

SANTOS, R. F. dos.Planejamento ambiental: teoria e prática. São Paulo; oficina de Textos, 2004.

WHATELY, M.; HERCOWITZ, M. Serviços Ambientais: conhecer, valorizar e cuidar. Subsídios para a proteção dos mananciais de São Paulo. São Paulo: Instituto Socioambiental, 2008.

VBA CONSULTORES S-C LTDA \& TECNOSOLO. Elaboração do plano de Gestao integrada da bacia do rio Pitumbu. Versão final dos relatórios. Natal: secretaria de Estado dos Recursos Hidrícos. CD, 2005. 